\title{
Presentación de un caso novedoso de síndrome de dificultad respiratoria aguda neonatal con infección por SARS-CoV-2: posible transmisión perinatal
}

\author{
A novel case of neonatal acute respiratory distress syndrome with SARS-CoV-2 \\ infection: potential perinatal transmission
}

\author{
Dra. Ezgi Yangin Ergon ${ }^{a}$, Dra. Sinem Akbay ${ }^{a}$ Dra. Gokce Aytemiz ${ }^{b}$, Dra. Esma C. Avcı Çelik \\ Dra. Arzu Çalıskan Polat ${ }^{b}$ Dra. Zuhal Umitc y Dra. Sebnem Paytoncu ${ }^{d}$
}

\section{RESUMEN}

La enfermedad por coronavirus de 2019 (COVID-19), causada por el coronavirus 2 del síndrome respiratorio agudo grave (SARS-CoV-2), se convirtió en la primera pandemia del siglo XXI. La infección por SARS-CoV-2 se transmite principalmente a través de las gotículas. Si bien se han informado algunos casos de transmisión perinatal, no es claro si estas infecciones fueron resultado de la vía de contagio transplacentario o transcervical o de la exposición ambiental.

En este artículo, presentamos el caso de un recién nacido que falleció por síndrome de dificultad respiratoria aguda neonatal con compromiso pulmonar grave. El bebé nació por cesárea de una madre con una PCR positiva para COVID-19y se detectó que tenía una PCR positiva para COVID-19 mediante un hisopado nasofaríngeo en el transcurso de las 24 horas posteriores al parto debido a una sospecha de transmisión transplacentaria del SARS-CoV-2 de la madre al feto.

Palabras clave: recién nacido, COVID-19, SARS-CoV-2, placenta, transmisión infecciosa, vertical.

http: / / dx.doi.org/ 10.5546/ aap.2021.e531

Texto completo en inglés:

http: / / dx.doi.org/10.5546/ aap.2021.eng.e531

Cómo citar: Yangin Ergon E, Akbay S, Aytemiz G, Avcı Celik CE, et al. Presentación de un caso novedoso de síndrome de dificultad respiratoria aguda neonatal con infección por SARS-CoV-2: posible transmisión perinatal. Arch Argent Pediatr 2021;119(5):e531-e535.

\begin{abstract}
a. Departamento de Neonatología.
b. Departamento de Pediatría.

c. Departamento de Infectología Pediátrica.

d. Departamento de Cardiología Pediátrica.

Hospital Manisa Şehir Hastanesi, Turquía.
\end{abstract}

\section{Correspondencia:}

Dra. Ezgi Yangin Ergon: yanginezgi@yahoo.com

Financiamiento: Ninguno.

Conflicto de intereses: Ninguno que declarar.

Recibido: $17-12-2020$

Aceptado: 13-4-2021

\section{INTRODUCCIÓN}

La enfermedad por coronavirus de 2019 (COVID-19), causada por el coronavirus 2 del síndrome respiratorio agudo grave (SARS-CoV-2), es una nueva enfermedad que se transmite a través de las gotitas respiratorias. Desde diciembre de 2019, la infección se ha propagado en todo el mundo. ${ }^{1}$

Cuando se detectó el SARS-CoV-2 por primera vez, no se observó evidencia de transmisión vertical de la madre al feto. ${ }^{2}$ Sin embargo, no es claro si se produce por contagio transplacentario o transcervical o por exposición ambiental. ${ }^{3}$ Hasta donde sabemos, actualmente existen dos publicaciones en la bibliografía que demostraron eficazmente la transmisión vertical. ${ }^{4}$

El caso que presentamos en este artículo corresponde a un recién nacido con compromiso pulmonar grave. Su madre tenía COVID-19, y se detectó COVID-19 en el bebé en el transcurso de las 24 horas posteriores al parto con sospecha de transmisión transplacentaria de SARS-CoV-2.

\section{A PROPÓSITO DE UN CASO}

Se trató de un bebé de sexo masculino nacido a las 34 semanas de gestación, con un peso al nacer de 2460 gramos, de una madre de 34 años que era positiva para COVID-19 y tenía fiebre, trombocitopenia y linfopenia y cuya tomografía computada de tórax mostraba neumonía bilateral por COVID-19. El bebé nació por cesárea de urgencia, ya que la madre presentó hemorragia vaginal y se le administró presión positiva continua nasal (PPCn) con una $\mathrm{FiO}_{2}$ del $30 \%$. Luego se lo monitoreó en una habitación aislada con presión negativa. El puntaje de Apgar al primer y quinto minuto fue de 4 y 7 , respectivamente. La frecuencia cardíaca era de 140 / min; la presión arterial (PA), 64/33 (37) $\mathrm{mmHg}$; la frecuencia respiratoria, $64 / \mathrm{min}$ y la $\mathrm{SpO}_{2}, 96 \%$ con una PPCn a los $30 \mathrm{~min}$. Las pruebas funcionales hepáticas fueron normales 
y las proteínas de la fase aguda (PFA) fueron negativas a las 6 horas de vida. Sin embargo, la linfopenia y la trombocitopenia estaban en valores limítrofes (Tabla 1). La serología del panel TORCH (toxoplasmosis, otros, rubéola, citomegalovirosis y herpes) fue normal y la prueba de Coombs directa fue negativa. El valor del dímero $D$ era de $6,59 \mu \mathrm{g} / \mathrm{ml}$. El panel de trombosis era normal. En la radiografía de tórax, se observaron opacidades en vidrio esmerilado bilaterales (Figura 1). Dado que no fue posible descartar la presencia de neumonía congénita, se inició la administración de ampicilina y gentamicina. Debido a que la madre tenía COVID-19, al bebé se le hizo un hisopado nasal (tras la limpieza posterior al nacimiento) en dos ocasiones con un intervalo de 24 horas. Según los resultados de esta prueba, el bebé también tenía COVID-19. ${ }^{5}$

Dado que el requerimiento de $\mathrm{FiO}_{2}$ siguió siendo superior al $40 \%$ a pesar de recibir asistencia respiratoria, al bebé se le administró surfactante (Curosurf, Chiesi, EE. UU.) con el método INSURE (intubación-surfactante-extubación). Sin embargo, al segundo día, se lo intubó y se le administró ventilación mecánica (modo $\mathrm{A} / \mathrm{C}$; presión inspiratoria máxima [PIM]: $22 \mathrm{cmH}_{2} \mathrm{O}$; presión positiva al final de la espiración [PPFE]: $5 \mathrm{cmH}_{2} \mathrm{O}$; frecuencia: 40; tiempo de inspiración: 0,$35 ; \mathrm{FiO}_{2}$ del $40 \%$, con un respirador Leoni plus de Heinen + Löwenstein) debido a taquipnea y tiraje subcostal e intercostal a pesar de recibir asistencia respiratoria nasal. Se le administró una segunda dosis de surfactante. El resultado del ecocardiograma se informó como normal. Al tercer día, el resultado de las PFA fue positivo. Se aumentó la concentración de ampicilina y se añadieron cefotaxima y azitromicina.

Al quinto día, el requerimiento de asistencia respiratoria y de aporte de oxígeno del paciente aumentó. Se le administró una tercera dosis de

TABLA 1. Hallazgos de laboratorio del recién nacido

\begin{tabular}{|c|c|c|c|c|c|c|}
\hline & Día 1 & Día 3 & Día 5 & Día 8 & Día 11 & Día 17 \\
\hline \multicolumn{7}{|l|}{ Hemograma } \\
\hline Leucocitos $\left(/ \mathrm{mm}^{3}\right)$ & 11400 & 6600 & 4300 & 3700 & 7000 & \\
\hline Linfocitos $\left(/ \mathrm{mm}^{3}\right)$ & 1420 & 1320 & 500 & 1340 & 1440 & \\
\hline Neutrófilos $\left(/ \mathrm{mm}^{3}\right)$ & 8760 & 4260 & 3110 & 1800 & 4930 & \\
\hline Plaquetas $\left(/ \mathrm{mm}^{3}\right)$ & 73000 & 71000 & 70000 & 65000 & 82000 & \\
\hline Eritrocitos $\left(10^{3} / \mathrm{mm}^{3}\right)$ & 5360 & 4950 & 3620 & 3480 & 4430 & \\
\hline $\mathrm{Hb}(\mathrm{g} / \mathrm{dl})$ & 19 & 17,6 & 13 & 11 & 14,2 & \\
\hline Hematocrito $(\%)$ & 54 & 51,2 & 39,6 & 34,5 & 41,8 & \\
\hline \multicolumn{7}{|l|}{ Análisis bioquímico de sangre } \\
\hline $\operatorname{AST}(\mathrm{U} / 1)^{1}$ & 55 & 91 & 95 & 92 & & \\
\hline $\operatorname{ALT}(\mathrm{U} / 1)$ & 6 & $<5$ & 6 & 6 & & \\
\hline $\mathrm{CK}(\mathrm{U} / 1)$ & 290 & & & 49 & & \\
\hline Troponina I (ng/ml) & & & & 0,3 & & \\
\hline PCR (mg/l) & $<5$ & 11,7 & 16,1 & 4,6 & 2,9 & \\
\hline \multicolumn{7}{|l|}{ Coagulación } \\
\hline $\mathrm{TP}(\mathrm{s})$ & 24,1 & & 17,5 & & & \\
\hline TP-RIN & 1,8 & & 1,29 & & & \\
\hline TTPa (s) & 62,5 & & 47 & & & \\
\hline Dímero D (ug/ml) & 6,59 & & 5,2 & & & \\
\hline Proteína C (\%) & & & 46,8 & & & \\
\hline Proteína S (\%) & & & 30,8 & & & \\
\hline Antitrombina III (mg/dl) & & & 30,7 & & & \\
\hline \multicolumn{7}{|l|}{ Cultivo } \\
\hline Hemocultivo & negativo & negativo & negativo & & negativo & \\
\hline Urocultivo & & negativo & negativoz & & & \\
\hline Aspirado traqueal & & & negativo & & negativo & negativo \\
\hline \multicolumn{7}{|l|}{ Prueba de COVID-19 } \\
\hline PCR nasal & +++ & +++ & & +++ & +++ & +++ \\
\hline $\operatorname{IgM}$ & & & +++ & & & \\
\hline $\operatorname{IgG}$ & & & +++ & & & \\
\hline
\end{tabular}

Hb: hemoglobina; AST: aspartato aminotransferasa; ALT: alanina aminotransferasa; CK: creatina-cinasa; PCR: proteína C-reactiva; TP: tiempo de protrombina; TP-RIN: tiempo de protrombina-razón internacional normalizada; TTPa: tiempo de tromboplastina parcial activado; PCR: reacción en cadena de la polimerasa. 
surfactante. Las pruebas de anticuerpos IgM e IgG de la COVID-19 fueron positivas. Las PFA aumentaron, y los valores de trombocitopenia y linfopenia fueron más pronunciados (Tabla 1). Se inició la administración de vancomicina y meropenem debido a la sospecha de sepsis intrahospitalaria. Además, tanto el paciente como la madre tenían trombocitopenia, por lo que no fue posible descartar una trombocitopenia aloinmune neonatal; en consecuencia, se le administró inmunoglobulina intravenosa.

\section{Figura 1. Radiografía de tórax. Ventilación nasal. Día 1}

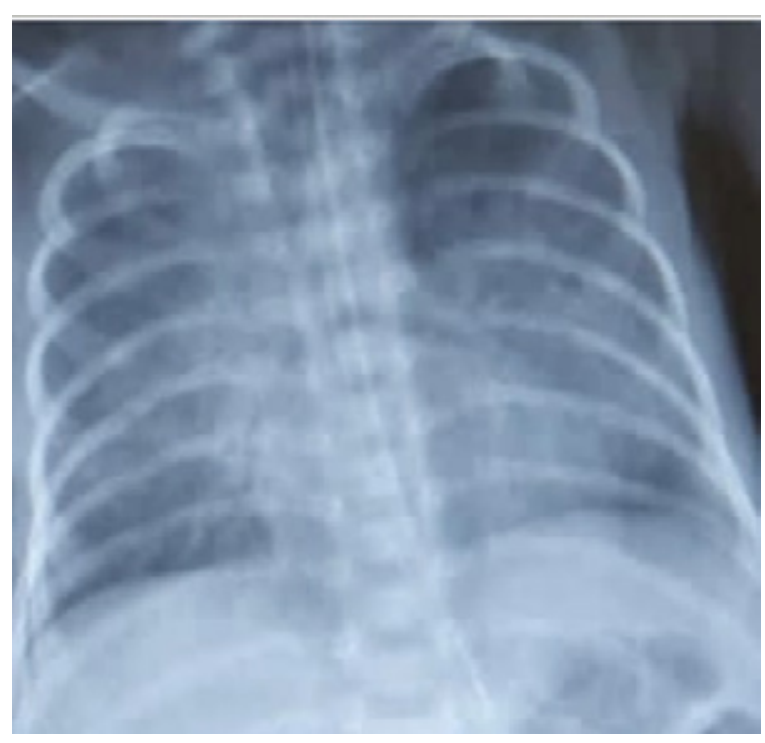

FIgURA 2. Radiografía de tórax. Ventilación de alta frecuencia. Día 7

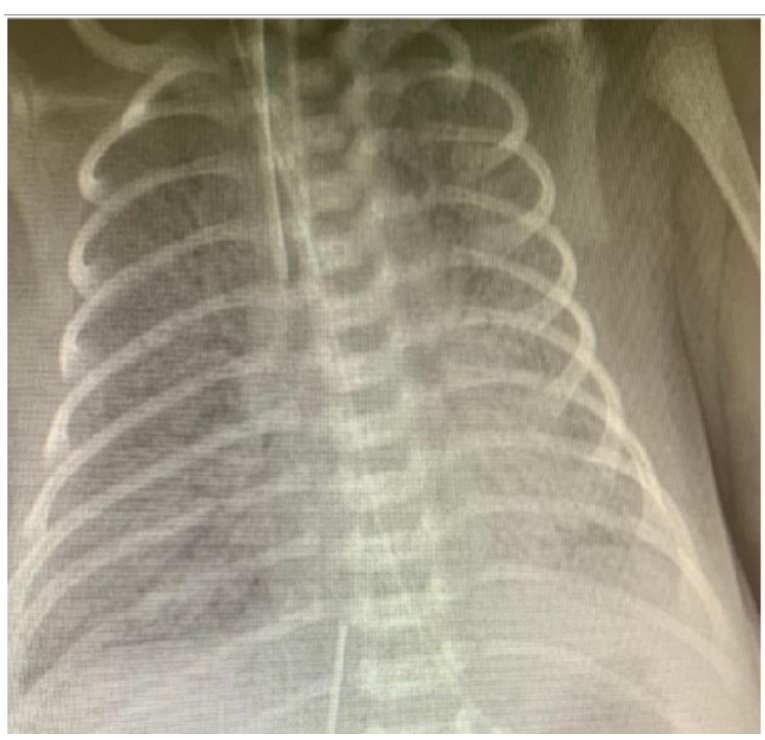

Al séptimo día, el paciente requirió la administración de presión elevada mediante ventilación mecánica convencional (PIM: $27 \mathrm{cmH}_{2} \mathrm{O}$ y presión media de la vía aérea [PMVA]: $12 \mathrm{cmH}_{2} \mathrm{O}$ ). Se inició la ventilación de alta frecuencia oscilatoria (VAFO) (PMVA: $14 \mathrm{cmH}_{2} \mathrm{O}$; frecuencia: 10; amplitud: 30 y FiO del $80 \%$ ) (Figura 2). Durante el seguimiento, se aumentó la VAFO gradualmente. Se administraron otras dos dosis de surfactante debido a la degradación secundaria del surfactante. Mientras tanto, en el ecocardiograma se observó hipertensión pulmonar (HP) grave. Se inició la administración de dopamina, dobutamina y sildenafilo. El paciente tenía un índice de oxigenación de 25. A pesar de la administración de la VAFO y de las dosis repetidas de surfactante, el requerimiento de $\mathrm{FiO}_{2}$ del paciente siguió aumentando y su cuadro clínico se deterioró incluso más rápidamente tras el sexto día. ${ }^{6}$ Se inició la administración de óxido nítrico inhalado $(\mathrm{ONi})$. Fue posible reducir el requerimiento de $\mathrm{FiO}_{2}$ al $65 \%$ con el ONi. Se hizo una maniobra de reclutamiento alveolar como parte de la VAFO para el síndrome de dificultad respiratoria aguda (SDRA), mientras se aumentó gradualmente la PMVA a $30 \mathrm{cmH}_{2} \mathrm{O}$ (presión de apertura) y se redujo a $24 \mathrm{cmH}_{2} \mathrm{O}$ (presión de cierre) con intervalos de 2-3 minutos, en cuyo contexto se usó una PMVA de $26 \mathrm{cmH}_{2} \mathrm{O}$, ya que se consideró la presión ideal. Como resultado, fue posible reducir el requerimiento de $\mathrm{FiO}_{2}$ al $55 \%$ (Figura 3). Se consideró que el paciente tenía SDRA neonatal grave conforme a la definición

FIgURA 3. Radiografía de tórax. Ventilación de alta frecuencia + óxido nítrico + maniobra de reclutamiento alveolar. Día 8

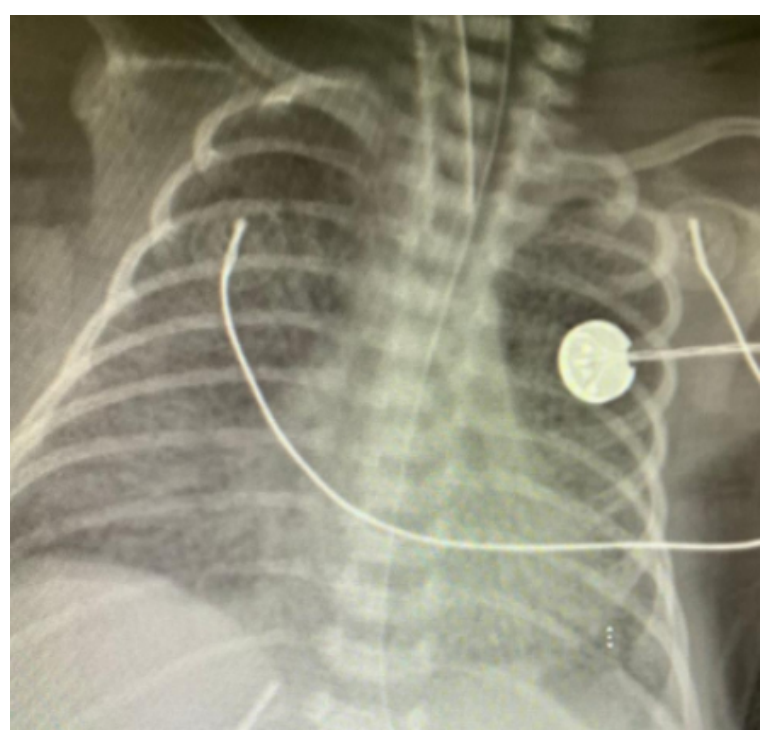


de Montreux. ${ }^{7}$ Dado su estado inestable, no se lo consideró apto para recibir oxigenación por membrana extracorporal y su seguimiento continuó con la asistencia disponible. Se repitieron las PCR con aspirados traqueales y se detectó COVID-19.5

El día 11, a pesar de tener PFA negativas, seguía con linfopenia y trombocitopenia, pero no se observó proliferación bacteriana en el hemocultivo, el urocultivo ni en los cultivos de aspirado traqueal. Se inició la administración de lopinavir-ritonavir como tratamiento antiviral para la COVID-19. Se intubó al paciente mientras recibía VAFO más ONi, pero su estado general era malo, con un requerimiento de $\mathrm{FiO}_{2}$ del $90 \%$ y $\mathrm{SpO}_{2}$ del $80 \%$ al $85 \%$. El paciente no respondió al tratamiento de apoyo y lamentablemente falleció en el día 17.

La madre del bebé estuvo hospitalizada durante tres días tras el parto y recibió el alta para continuar con el tratamiento, ya que no tenía dificultad respiratoria. Ya no tenía síntomas hacia el día 14 de su cuarentena y luego tuvo una PCR negativa para COVID-19.

\section{DISCUSIÓN}

Los estudios que demuestran la transmisión vertical son limitados en la bibliografía existente. ${ }^{4}$ Sin embargo, Shah y col., publicaron una clasificación que incluye la "definición de caso de SARS-CoV-2" y evalúa la posible transmisión perinatal. ${ }^{8}$ Según esto, se incluyó a nuestro paciente en la categoría "infección neonatal adquirida durante el parto, confirmada". No fue posible incluir al paciente en la categoría definitiva de "infección neonatal congénita" porque no se pudo obtener una muestra del cordón umbilical ni del líquido amniótico. Sin embargo, no se puede descartar una posible transmisión perinatal, ya que nuestro paciente tenía compromiso pulmonar grave sintomático y manifestaciones clínicas de SARS-CoV-2, y tanto la madre como el bebé tenían síntomas y sus análisis de sangre coincidían con COVID-19. Se sabe que la enzima convertidora de la angiotensina 2 (ECA-2) es la receptora objetivo del SARS-CoV-2 y que está abundantemente presente en la placenta. ${ }^{9}$ Según estudios en animales, la concentración de ECA-2 llega a su máximo entre el final del embarazo y los primeros días después del parto. ${ }^{9}$ Con estos datos, se confirma la transmisión transplacentaria, en especial durante las últimas semanas de la gestación. Además, el hecho de que, en este estudio, la viremia neonatal fuera mortal y más grave que la viremia materna contradice el concepto de carga viral, y esto podría ser el resultado de la concentración placentaria más alta de ECA-2 observada durante los primeros días después del parto.

La probabilidad de desarrollar formas graves de SARS-CoV-2 está asociada con la expresión de ECA-2 en algunas personas. ${ }^{10}$ La función del estrógeno en el aumento regulado de la ECA-2 y la circulación rápida de esta en los niños podría explicar las formas menos graves de infección por SARS-CoV-2 observadas en ellos. ${ }^{10}$ No obstante, aparte de la edad, el sexo y las comorbilidades, también se describieron algunos factores de riesgo de laboratorio para las formas graves del SARS-CoV-2. ${ }^{11}$ Estos están relacionados con hiperinflamación, inmunodesregulación e hipercoagulopatía. En la bibliografía, se informaron concentraciones altas de ferritina, IL-6 y dímero $\mathrm{D}$ en algunos pacientes con síntomas clínicos graves. ${ }^{12}$ Asimismo, se observó que la linfopenia presente en el $72 \%$ al $85 \%$ de los casos graves de COVID-19 es la clave de la infección por SARS-CoV-2. Un recuento bajo de linfocitos, un recuento elevado de leucocitos y un índice de neutrófilos/linfocitos (INL) alto podrían indicar una enfermedad de curso grave. ${ }^{13}$ En nuestro paciente, la disminución progresiva del recuento de linfocitos y el aumento del INL, además del sexo del paciente, indicaron la presencia de una infección por SARS-CoV-2 grave.

En este caso, es muy difícil determinar si la dificultad respiratoria fue a causa del SARS$\mathrm{CoV}-2$ o del parto prematuro. También es posible que la infección por SARS-CoV-2 de la madre fuera el motivo de la cesárea urgente y del parto prematuro. La presencia del SARS-CoV-2 quedó respaldada por los resultados positivos de las repetidas PCR para detectar la COVID-19, la linfopenia pronunciada concurrente y el aumento de la dificultad respiratoria, que se tornó más marcada el día 15. Además, el paciente mostró HP persistente grave y SDRA neonatal con respuesta inadecuada a la asistencia respiratoria. En la bibliografía existente, solo se ha informado el caso de un recién nacido con síntomas respiratorios graves y neumonía grave, similar a nuestro paciente. $^{14}$

Según algunos estudios, las variantes genéticas que causan pérdida de la función del gen TLR7 del cromosoma $X$ produjeron SARS-CoV-2 grave y mortal al afectar las respuestas del interferón tipo 1 y $2 .{ }^{15}$ Sin embargo, no se detectaron variaciones en los exones del gen TLR7. Aún quedan muchas preguntas sin respuesta sobre 
la gravedad de la enfermedad transmitida y su existencia y el momento de la transmisión vertical. En este artículo, se informa sobre el caso de un recién nacido con SDRA neonatal mortal secundario a viremia neonatal, en el contexto del cual la presencia de una posible transmisión perinatal quedó respaldada por varios aspectos. Si bien este caso nos dio la oportunidad de abordar un cuadro clínico que no se ha descrito a menudo en la bibliografía, también generó nuevas preguntas sobre el SARS-CoV-2 neonatal y su evolución clínica.

\section{REFERENCIAS}

1. Huang C, Wang Y, Li X, Zhao J, et al. Clinical features of patients infected with 2019 novel coronavirus in Wuhan, China. Lancet. 2020; 395(10223):497-506.
2. Alserehi H, Wali G, Alshukairi A, Alraddadi B. Impact of Middle East respiratory syndrome coronavirus (MERS$\mathrm{CoV}$ ) on pregnancy and perinatal outcome. BMC Infect Dis. 2016; 16:105.

3. Zamaniyan M, Ebadi A, Aghajanpoor Mir S, Rahmani $Z$, et al. Preterm delivery, maternal death, and vertical transmission in a pregnant woman with COVID-19 infection. Prenat Diagn. 2020; 40(13):1759-61.

4. Patanè L, Morotti D, Giunta MR, Sigismondi C, et al. Vertical transmission of coronavirus disease 2019: severe acute respiratory syndrome coronavirus 2 RNA on the fetal side of the placenta in pregnancies with coronavirus disease 2019-positive mothers and neonates at birth. Am J Obstet Gynecol MFM. 2020; 2(3):100145.

5. Yu XS, Sun S, Shi Y, Wang H, et al. SARSCoV-2 viral load in sputum correlates with risk of COVID-19 progression. Crit Care. 2020; 24(1):170.

6. Bollaga WB, Gonzales JN. Phosphatidylglycerol and surfactant: A potential treatment for COVID-19? Med Hypotheses. 2020; 144:110277. 